\title{
Utilization of Coal Bottom Ash a Low-Cost Adsorbent for the Removal Acid Red 114 Dye
}

\author{
Kuntari $^{a^{*}}$, Nurul Hidayat Aprilita ${ }^{\mathrm{b}}$ dan Suherman ${ }^{\mathrm{b}}$ \\ ${ }^{a}$ Chemical Analysis Program, Faculty of Mathematic and Natural Sciences, \\ Islamic University of Indonesia, Yogyakarta, Indonesia, 55584 \\ ${ }^{b}$ Department of Chemistry Program, Faculty of Mathematic and Natural Sciences, \\ Gadjah Mada University, Yogyakarta, Indonesia, 55281 \\ *e-mail:chemist.tari@gmail.com
}

\begin{abstract}
A research about adsorption of acid red 114 using coal bottom ash has been conducted. This research was aimed to examine the ability of coal bottom ash in acid red 114 adsorption. Some adsorption parameters i.e. dosage adsorbent, contact time and $\mathrm{pH}$ medium were examined in the adsorption processes. The characterization of coal bottom ash was determined using X-Ray Diffraction. Acid red 114 concentration is measured by using UV-Visible spectrophotometer. The adsorption percentage of acid red 114 on the coal bottom ash is $91.2 \%$ at $\mathrm{pH} \mathrm{1.5}$; contact time 80 min, acid red 114 concentration $10 \mathrm{mg} / \mathrm{L}$ for every $1.5 \mathrm{~g}$ bottom ash.
\end{abstract}

Keywords : coal bottom ash, acid red 114 and adsorption

\begin{abstract}
ABSTRAK
Telah dilakukan penelitian tentang adsorpsi acid red 114 menggunakan abu dasar batubara. Penelitian ini bertujuan untuk mempelajari kemampuan abu dasar batubara dalam mengadsorpsi acid red 114. Beberapa parameter adsorpsi seperti dosis adsorben, waktu kontak dan $\mathrm{pH}$ medium dikaji dalam proses adsorpsi. Karakterisasi abu dasar batubara dilakukan dengan menggunakan Difraksi Sinar-X. Konsentrasi acid red 114 ditentukan secara kuantitatif dengan menggunakan spektrofotometer UV-sinar tampak. Hasil adsorpsi terhadap larutan acid red 114 mencapai optimum dengan persentase adsorpsi sebesar 91,2 \% ketika kondisi $\mathrm{pH}$ 1,5; waktu kontak 80 menit, konsentrasi acid red 114 sebesar $10 \mathrm{mg} / \mathrm{L}$ dan abu dasar batubara yang digunakan $1,5 \mathrm{~g}$.
\end{abstract}

Kata-kata kunci: abu dasar batubara, acid red 114 dan adsorpsi

\section{Pendahuluan}

Salah satu jenis limbah padat yang dihasilkan oleh Pembangkit Listrik Tenaga Uap (PLTU) berbahan bakar batubara adalah abu dasar batubara. Pada tahun 2019 diperkirakan limbah abu dasar batubara yang dihasilkan oleh PLTU di Indonesia mencapai 8,7 juta ton (Marsyaf,
2016). Hal tersebut tentunya menjadi masalah tersendiri ketika abu dasar batubara tidak dikelola karena akan mencemari lingkungan sekitar penimbunan.

Abu batubara berbentuk partikel halus amorf yang bersifat pozzolan, dapat bereaksi dengan kapur pada suhu kamar 
dengan media air membentuk senyawa yang bersifat mengikat (Sukandarrumidi, 2006). Hasil penelitian-penelitian sebelumnya menginformasikan bahwa abu dasar batubara memiliki kapasitas adsorpsi yang baik untuk menyerap ion logam berat dan zat organik. Hal tersebut didukung oleh hasil penelitian Sunarti (2008) yang menyatakan bahwa komponen mayor abu dasar adalah silika $\left(\mathrm{SiO}_{2}\right)$ dan alumina $\left(\mathrm{Al}_{2} \mathrm{O}_{3}\right)$, sedangkan komponen minor berupa besi (III) oksida $\left(\mathrm{Fe}_{2} \mathrm{O}_{3}\right)$, kalsium oksida $(\mathrm{CaO})$, magnesium oksida $(\mathrm{MgO})$, natrium oksida $(\mathrm{NaO})$ dan kalium oksida $\left(\mathrm{K}_{2} \mathrm{O}\right)$. Dari data tersebut dapat diketahui bahwa abu dasar batubara berpotensi digunakan sebagai adsorben.

Aplikasi material adsorben salah satunya dalam pengolahan limbah industri tekstil. Pengolahan limbah penting dilakukan karena zat warna tekstil yang digunakan biasanya memiliki biodegradabilitas rendah dalam lingkungan aerob dan kemungkinan dapat terurai pada kondisi anaerob membentuk senyawa amina aromatik yang berpotensi menyebabkan kanker (Panswad, 2000).

Salah satu zat warna yang digunakan dalam proses pewarnaan tekstil adalah acid red 114. Acid red 114 memiliki gugus azo (Gambar 1) yang labil dan mudah mengalami reaksi pemutusan ikatan rangkap. Produk dekomposisi berupa amina aromatik yang berefek akut dan kronis pada manusia. Acid red 114 memiliki gugus $-\mathrm{SO}_{3}{ }^{-}$dan $-\mathrm{OH}^{-}$yang menyebabkan kelarutannya dalam air tinggi sehingga tidak mudah dilakukan proses flokulasi dan koagulasi.

Pengolahan limbah cair industri tekstil dengan metode flokulasi dan koagulasi memerlukan banyak flokulan dan koagulan untuk menghilangkan zat warna dengan konsentrasi tinggi sehingga penggunaan metode ini akan meningkatkan biaya yang dikeluarkan untuk pengolahan limbah. Oleh karena itu, metode yang dipilih dalam penelitian ini adalah metode adsorpsi, karena dinilai efektif dan ekonomis untuk mengatasi keberadaan acid red 114 dalam limbah tekstil.

\section{Tujuan Penelitian}

Tujuan dari penelitian ini adalah mempelajari pengaruh waktu interaksi, berat adsorben dan $\mathrm{pH}$ medium dalam adsorpsi zat warna acid red 114 menggunakan abu dasar batubara.

\section{Metode Penelitian}

\section{Bahan Penelitian}

Bahan-bahan yang digunakan dalam penelitian ini adalah acid red 114, asam klorida, natrium hidroksida, buffer 4 dan 7, abu dasar batubara PLTU Paiton, 
akuabides, akuades dari Laboratorium Kimia Dasar FMIPA UGM.

\section{Peralatan Penelitian}

Peralatan yang digunakan dalam penelitian ini meliputi beberapa peralatan gelas, neraca analitik merek Shimadzu, ayakan 400 mesh, lumpang, mortar, furnace, corong buchner, centrifuge, magnetic stirer, kertas saring Whatman 42, desikator, $\mathrm{pH}$ meter, spektrofotometer UVvis Spectronic 20D+ (pengukuran absorbansi pada panjang gelombang optimum acid red $114, \lambda=500 \mathrm{~nm}$ ) dan difraktometer sinar-X Shimadzu XRD 6000 menggunakan radiasi $\mathrm{Cu} \mathrm{K} \alpha$ $(\lambda=0,154 \mathrm{~nm})$ dan scan dilakukan dari $2^{\circ}$ sampai $80^{\circ}$ dengan laju $2^{\circ}$ menit.

\section{Prosedur Penelitian}

Preparasi dan karakterisasi abu dasar batubara

Abu dasar batubara dicuci dengan akuabides kemudian dikeringkan pada temperatur $105^{\circ} \mathrm{C}$ selama 24 jam untuk menghilangkan air. Selanjutnya, abu dasar batubara diayak dengan ayakan 400 mesh dan diaktifkan pada temperatur $500^{\circ} \mathrm{C}$ selama 15 menit untuk meningkatkan kapasitas adsorpsi. Abu dasar batubara yang dihasilkan kemudian disimpan dalam desikator sampai diperlukan dalam proses adsorpsi dan karakterisasi. Abu dasar batubara dikarakterisasi menggunakan difraksi sinar-X untuk mengidentifikasi jenis mineral penyusunnya.

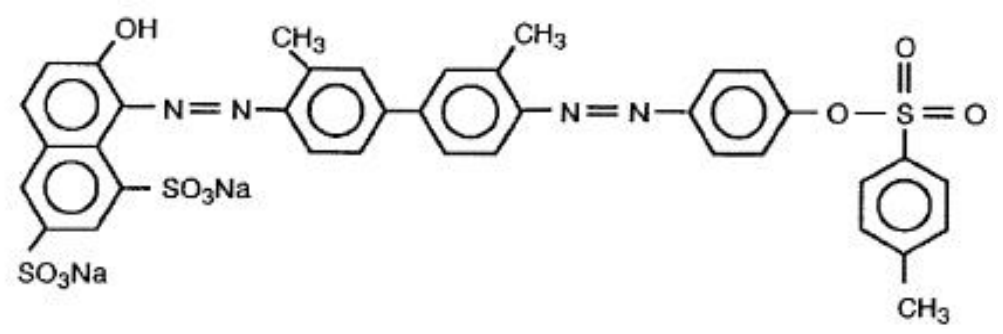

Gambar 1. Struktur Acid Red 114

Adsorpsi acid red 114 pada abu dasar batubara

Parameter adsorpsi yang dipelajari meliputi variasi waktu kontak, berat adsorben dan $\mathrm{pH}$ medium. Waktu optimum ditentukan dengan melakukan variasi waktu kontak selama 10, 20, 30, 40, 50, 60, 70, 80 dan 90 menit. Berat optimum ditentukan dengan melakukan variasi berat adsorben yaitu 0,$5 ; 1,0 ; 1,5 ; 2,0$ dan 2,5 gram. Sementara pengaruh $\mathrm{pH}$ larutan dipelajari dengan melakukan variasi $\mathrm{pH}$ medium yaitu sebesar 1,5; 3,5; 5,5; 7,5 dan 9,5 dengan melakukan penambahan larutan $\mathrm{HCl}$ atau $\mathrm{NaOH}$. Setelah adsorpsi, suspensi diusingkan selama 3 menit dengan kecepatan 3000 rpm dan disaring dengan kertas saring Whatman 42. Filtrat diukur absorbansinya Utilization of Coal Bottom Ash a Low-Cost Adsorbent for the Removal Acid Red 114 Dye 
menggunakan spektrofotometer sinar tampak pada panjang gelombang optimum larutan acid red 114 dan persentase adsorpsi dihitung dengan persamaan (1).

$$
\% \text { Adsorpsi }=\frac{\text { Zat Warna } \text { teradsorpsi }(m g)}{\text { Zat Warna } a \text { awal }(m g)} \times 100 \% \text { (1) }
$$

\section{Pembahasan}

\section{Karakterisasi Abu Dasar Batubara dengan Metode Difraksi Sinar-X}

Abu dasar batubara yang digunakan (Gambar 2.) dikarakterisasi menggunakan difraksi sinar-X. Berdasarkan hasil XRD abu dasar yang ditunjukkan pada Gambar 2, puncak-puncak difraktogram muncul pada sudut difraksi 21,0774; 24,2627; 26,2871; 35,$88 ; 36,72 ; 50,3583^{\circ}$ dan $68,4037^{\circ}$ yang bersesuaian dengan harga $\mathrm{d}$ berturut-turut 4,$2116 ; 3,66542 ; 3,3133 ; 2,5008 ; 2,4455$; 1,81055 dan 1,37037 ̊. Harga d berturutturut 4,$2116 ; 3,66542 ; 3,3133$; dan 1,81055 $\AA$ adalah harga-harga d yang bersesuaian dengan mineral kuarsa $\left(\mathrm{SiO}_{2}\right)$, sedangkan puncak-puncak dengan harga $d$ 2,5008; 2,4455 dan 1,37037 $\AA$ adalah harga-harga d yang sesuai untuk mineral mullit $\left(\mathrm{Al}_{2} \mathrm{O}_{3}\right)$.

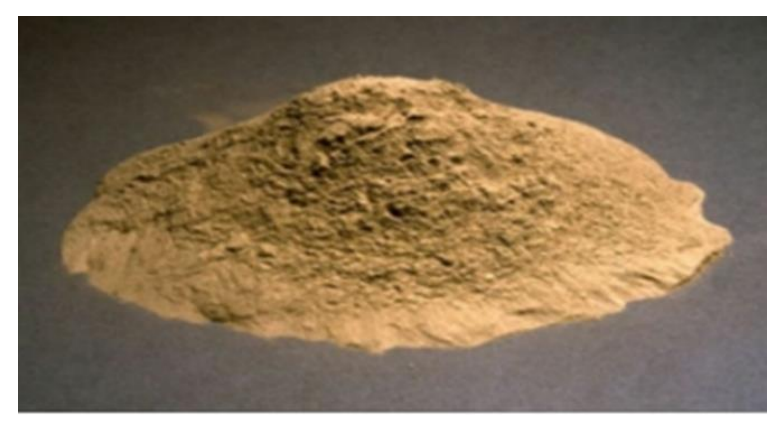

Gambar 2. Abu Dasar Batubara

Pada Gambar 3 juga terlihat puncak untuk mineral kuarsa yaitu pada sudut difraksi 26,2871 ${ }^{\circ}$ lebih tinggi jika dibandingkan puncak untuk mineral mullit pada sudut difraksi $36,72^{\circ} ; 50,3583^{\circ}$ dan $68,4037^{\circ}$. Intensitas puncak mineral kuarsa lebih besar daripada intensitas puncak mineral mullit menunjukkan bahwa mineral kuarsa $\left(\mathrm{SiO}_{2}\right)$ merupakan komponen mayor dari abu dasar batubara.

\section{Pengaruh Waktu Kontak}

Pada tahap ini larutan acid red 114 diinteraksikan dengan sejumlah abu dasar batubara pada berbagai variasi waktu. Hasil adsorpsi pada tahap ini disajikan pada Gambar 4.

Berdasarkan Gambar 4 terlihat pada tahap awal terjadi adsorpsi yang relatif lebih cepat. Hasil tersebut dikarenakan pada tahap awal interaksi, masih terdapat banyak situs 
aktif dari abu dasar batubara dan adsorbat pada permukaan adsorben. Persen memungkinkan sebagai tempat untuk adsorpsi pada waktu interaksi 90 menit terjadinya adsorpsi sedangkan tahap mengalami penurunan, sehingga waktu setelahnya, sisa situs aktif sulit untuk interaksi 80 menit ditetapkan sebagai waktu ditempati adsorbat karena adanya gaya optimum adsorpsi.

tolak-menolak antara molekul-molekul

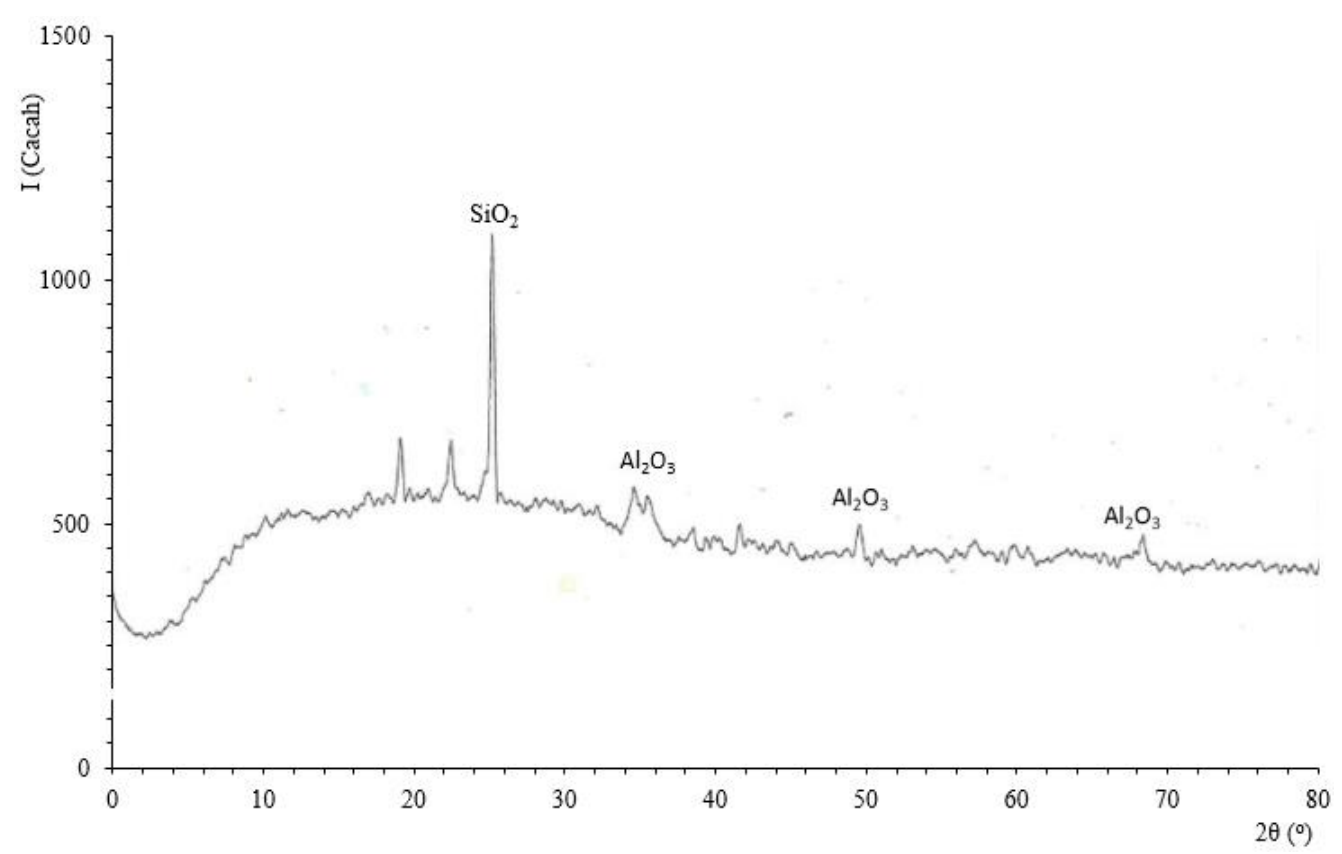

Gambar 3. Difraktogram Sinar-X Abu Dasar Batubara

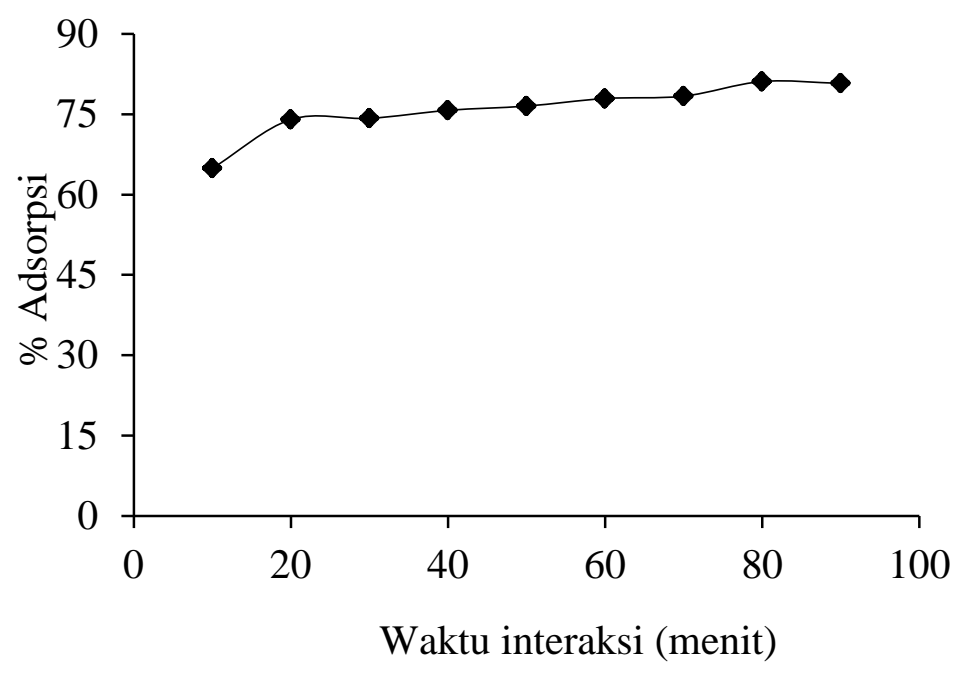

Gambar 4. Pengaruh Waktu Interaksi terhadap Adsorpsi

Utilization of Coal Bottom Ash a Low-Cost Adsorbent for the Removal Acid Red 114 Dye 
Pengaruh Berat Adsorben

acid red 114 dengan abu dasar batubara Kajian pengaruh berat abu dasar dengan berat yang bervariasi. Hasil batubara pada adsorpsi acid red 114 penelitian pada tahap ini ditunjukkan pada dilakukan dengan menginteraksikan larutan Gambar 5.

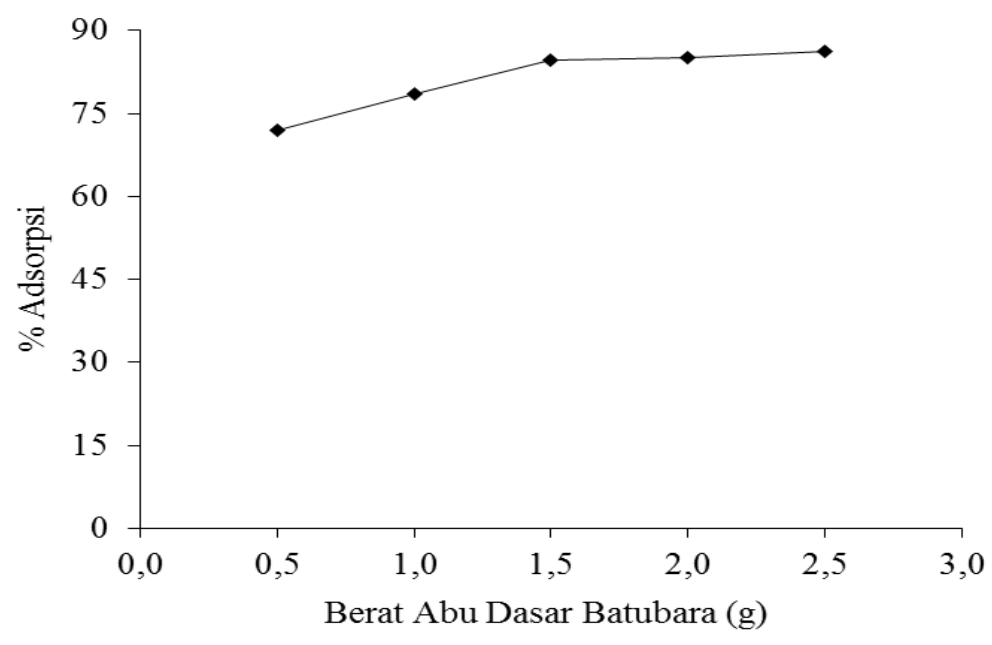

Gambar 5. Pengaruh Berat Abu Dasar Batubara terhadap Adsorpsi

Pengaruh pH

Kajian mengenai pengaruh $\mathrm{pH}$ pada adsorpsi abu dasar batubara terhadap acid red 114 dilakukan dengan menginteraksikan abu dasar batubara dengan larutan acid red
114 yang telah divariasi pHnya. Hasil penelitian pengaruh $\mathrm{pH}$ terhadap adsorpsi acid red 114 oleh abu dasar batubara disajikan pada Gambar 6.

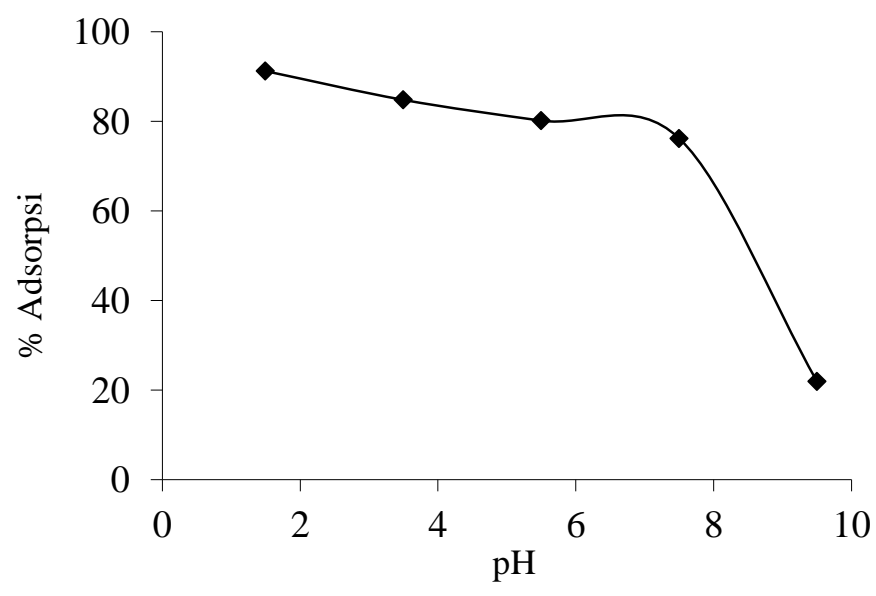

Gambar 6. Pengaruh $\mathrm{pH}$ terhadap Adsorpsi

Utilization of Coal Bottom Ash a Low-Cost Adsorbent for the Removal Acid Red 114 Dye 
$\mathrm{pH}$ larutan zat warna memegang peranan penting dalam proses adsorpsi secara keseluruhan, terutama pada kapasitas adsorpsi. $\mathrm{pH}$ dapat berpengaruh pada muatan permukaan adsorben, disosiasi gugus fungsi pada situs aktif adsorben dan struktur zat warna dalam larutan. acid red 114 memiliki gugus sulfonat (D-SO $\left.{ }_{3} \mathrm{Na}\right)$ ketika berada dalam lingkungan berair akan terdisosiasi (Persamaan 2).

$$
\mathrm{D}-\mathrm{SO}_{3} \mathrm{Na}+\mathrm{H}_{2} \mathrm{O} \longrightarrow \mathrm{D}-\mathrm{SO}_{3}{ }^{-}+\mathrm{Na}^{+}
$$

Muatan permukaan adsorben secara lebih jelas dapat ditentukan dengan zero point charge (ZPC). Prinsip ZPC adalah mendiskripsikan kondisi ketika densitas muatan elektrik pada permukaan sama dengan nol. Permukaan abu dasar batubara akan bermuatan positif ketika $\mathrm{pH}$ sistem lebih rendah dari $\mathrm{pH}_{\mathrm{zpc}}$ adsorben $(5,8)$ (Ahmed, 1972); bermuatan negatif ketika $\mathrm{pH}$ sistem berada di atas $\mathrm{pH}_{\mathrm{zpc}}$ dan tidak bermuatan ketika $\mathrm{pH}$ sistem sama dengan $\mathrm{pH}_{\mathrm{zpc}}$ (Stumm and Morgan,1996) seperti ditunjukkan pada Persamaan 3.

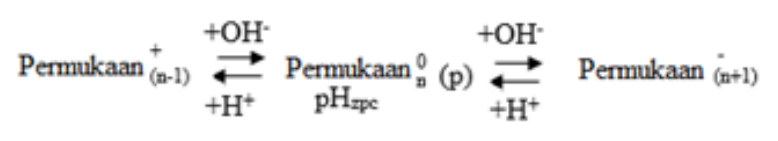

Utilization of Coal Bottom Ash a Low-Cost Adsorbent for the Removal Acid Red 114 Dye

(Kuntari, Nurul Hidayat Aprilita dan Suherman) 
114 sehingga dapat mengurangi kapasitas adsorpsi. Terlebih lagi ketika $\mathrm{pH}$ sistem di atas $\mathrm{pH}_{\mathrm{zpc}}$ abu dasar batubara, permukaan abu dasar batubara menjadi bermuatan negatif seperti yang tertulis pada Persamaan 6.

$--\mathrm{SiOH}+\mathrm{OH}^{-} \longrightarrow-\mathrm{SiO}^{-}+\mathrm{H}_{2} \mathrm{O}$

Pada $\mathrm{pH}$ sistem $=\mathrm{pH}_{\mathrm{zpc}}$ abu dasar batubara maka acid red 114 dengan permukaan abu dasar batubara akan saling tolak menolak.

\section{Kesimpulan}

Berdasarkan hasil penelitian adsorpsi zat warna acid red 114 menggunakan abu dasar batubara, maka dapat diambil kesimpulan bahwa waktu interaksi, berat adsorben dan $\mathrm{pH}$ media optimum adsorpsi zat warna acid red 114 menggunakan abu dasar batubara terjadi ketika waktu interaksi 80 menit, berat abu dasar sebesar 2,0 gram dan $\mathrm{pH}$ larutan 1,5.

\section{Daftar Pustaka}

Adamson, A.W., 1990, Physical Chemistry of Surface, Fifth Edition, John Wiley and Son Inc., New York.

Alzaydien, A.S., 2009, Adsorption of methylene blue from aqueous solution onto a low-cost natural Jordanian Tripoli. J. Am. Env. Sci., 5, 3, 197-208.
Aziz, M., 2006, Karakterisasi abu terbang PLTU Suralaya dan evaluasinya untuk refraktori. J. Tekmira., 36, 14, 1-8.

Gupta V. K., 2005, Removal of dyes from wastewater using bottom ash. J.Ind. Eng. Chem. Res., 44, 3655-3664.

Gupta V. K. Gupta., 2006, Removal and recovery of the hazardous azo dye acid orange 7 through adsorption over waste materials: bottom ash and de-oiled soya. J. Ind. Eng. Chem. Res., 45, 1446-1453.

Khan,T.A.,dkk., 2009, Utilization of fly ash as low-cost adsorbent for the removal of methylene blue, malachite green and rhodamine B dyes from textile wastewater. J. Environ Protect., 3, 11-22.

Leechart, P., Nakbanpote. W., dan Thiravetyan, P., 2009, Application of waste wood-shaving bottom ash for adsorption of azo reactive dye. $J$. Environ.Manag., 90, 912-920.

Marsyaf, M. I., 2016, ESDM Dorong Pemanfaatan Limbah Batubara, Koran Sindo, 17 Februari, 2016

Mukhtar S., 2003, Evaluation of bottom ash and composted manure blends as a soil amendment Material. J. Bio.Tech., 89, 217-228.

National Toxicology Program, 1991, Toxicology and Carcinogenesis of C.I. Acid Red 114 in F344/N Rats. Departement of Health and Human Services. 
Panswad, T., Luangdilok, W., 2000, Decolorization of reactive dyes with differentmolecular structures under different environmental conditions. $J$. Wat. Res, 34, 4177-4184.

Speiser, C. dkk., 2000, Morphological and chemical characterization of calciumhydrate phases, formed in alteration process of deposited municipal solid waste incinerator bottom ash. Environ. Sci. Technol., 34, 5030.

Stumm, W. and Morgan, J.J., 1995, Aquatic Chemistry: Chemical Equilibrium and Rates in Natural Waters, 3rd Ed. Wiley, New York. ISBN: 978-0-47151185-4, 1040.
Stumm, W. dan Morgan, J.J., 1981, Aquatic Chemistry, John Wiley and Son Inc., New York.

Sukandarrumidi, 2006, Batubara dan Pemanfaatannya, Pengantar Teknologi Batubara Menuju Lingkungan Bersih, Gadjah Mada University Press, Yogyakarata.

Sunarti, 2008, Pembuatan Adsorben Termodifikasi dari Abu Dasar Batubara dan Aplikasinya untuk Adsorpsi Logam Berat Timbal (Pb), Tesis S2 Jurusan Kimia FMIPA UGM,Yogyakarta. 